Araştırma Makalesi

Research Article

Geliş Tarihi: 07.01.2019

Received: 07.01.2019

Kabul Tarihi: 19.03.2019

Accepted: 19.03.2019

Karakılıç Yörük, N. (2019). Cameron ve Quinn örgüt kültürü ölçeğinin güvenirlik ve geçerliğinin test edilmesi. KOCATEPEIIIBF Dergisi, Haziran 2019, 21(1), 19-30.

\title{
CAMERON VE QUINN ÖRGÜT KÜLTÜRÜ ÖLÇEĞİNİN GÜVENİRLİK VE GEÇERLİĞİNİN TEST EDİLMESİ
}

NİLÜFER YÖRÜK KARAKILIÇ1

\begin{abstract}
ÖZ
Çalışmada Cameron ve Quinn örgüt kültürü ölçeğinin geçerliği ve güvenilirliği test edilmesi amaçlanmıştır. Toplumun tüm değerleri kültürel yapıyı oluşturur ve toplumun benimsediği kültür işletmelerin yapılarını da yakından ilgilendirir. Bu kapsamda işletmelerin varlığında bu derece önem arz eden bir unsurun ölçümünde kullanılan ölçekler de önem kazanmaktadır. Çalışmada incelediğimiz Rekabetçi değerler modeline dayalı Cameron ve Quinn örgüt kültürü ölçeğinde Klan, Adhokrasi, Hiyerarşi ve Piyasa kültürü olarak 4 kültür tipi tanımlanmıştır. Araştırmanın uygulaması Afyon ili mermer sektöründe faaliyetlerini sürdüren büyük ölçekli bir işletmede gerçekleştirilmiştir. İşletmede çalışan 270 işgörene anket uygulanmıș ve 246 sağlıklı veriye ulaşılmıștır. Veriler SPSS 16,0 paket programına girildikten sonra SPSS de güven analizi, Cronbach Alpha analizi ve faktör analizi yapılmış ve ölçeğin analizi için AMOS 19 programında yapısal eşitlik modellemesi birinci düzey doğrulayıcı faktör analizi gerçekleştirilmiştir. Yapılan araştırma sonuçlarında kültür ölçeğinin dört boyutu da geçerlik testinden geçmiştir.
\end{abstract}

Anahtar Kelimeler: Cameron ve Quinn Örgüt Kültürü Ölçeği, Yapısal Eşitlik Modeli

JEL Kodları: M14, C2

\section{TESTING RELIABILITY AND VALIDITY OF THE CAMERON AND QUINN ORGANIZATIONAL CULTURE SCALE}

\begin{abstract}
The study aimed to test the validity and reliability of the Cameron and Quinn organizational culture scale. All values of the society constitute the cultural structure and the culture that the society adopts is closely related to the structures of the enterprises. In this context, the scales used in the measurement of such an important element in the presence of enterprises gain importance. In the study, four culture types have been defined as Clan, Adhocracy, Hierarchy and Market Culture on Cameron and Quinn organizational culture scale. The application of the study was carried out in a large-scale enterprise operating in the marble sector of Afyon province. 270 employees were surveyed and 246 healthy data were obtained. The data were analyzed by SPSS 16.0 package program and then Cronbach alpha analysis and factor analysis were performed in SPSS. For the analysis of the scale, structural equation modeling first level confirmatory factor analysis was carried out in AMOS 19 program. In the results of the research, all four dimensions of the culture scale were validated.
\end{abstract}

Keywords: Cameron and Quinn Organizational Culture Scale, Structural Equation Model

JEL Codes: M14, C2

\footnotetext{
1 Dr. Öğretim Üyesi, Afyon Kocatepe Üniversitesi, İktisadi ve İdari Bilimler Fakültesi, İşletme Bölümü, nilyoruk@aku.edu.tr - ORCID: 0000-0002-6609-4068
} 


\section{Gíkiș}

Kültür toplumun içinde bulunduğu çevrenin tüm şartlarıdır. Aslında insan davranışlarına etki eden yazılı ve resmi olmayan kurallar bütünüdür. Kültür, literatürde en çok araştırılan kavramlar arasında yer almaktadır. Özellikle 1980 sonrası yapılan çalışmalarla beraber işletmeler için ne derece önemli olduğu daha iyi anlaşılmıştır. Kültür toplumdan işletmeye sirayet eden ve hem toplumdan topluma hem de işletmeden işletmeye değişen bir yapıdadır. Toplumun genel özelliklerini taşımakla birlikte her işletmenin kurum kültürünün oluşum süreci farklı şekillenmektedir. Hatta işletmelerin farklı departmanlarında yerleşmiş, işletmenin genel kültüründen ayrışan alt kültürler mevcut olabilmektedir. Kültür toplumsal anlamda, adet, gelenek, görenek, edebiyat, sanat, şiir, din, dil, resim, felsefe gibi unsurları kapsamına alırken; bir işletmede tüm iş yapma usulleri, hiyerarşik yapı, yönetim şekli, ödül-ceza sistemleri gibi tüm süreçlerini kapsamaktadır.

Kültür, ortak paylaşılan değerler bütünü olmakla toplumu ve toplumun bir parçası olan işletmeleri de yakından ilgilendirmektedir. İşletmeler toplumun sahip olduğu kültürel değerlerle şekillenmektedir. Çalışmada kültür ölçeklerinden biri olan Cameron ve Quinn örgüt kültürü ölçeği kullanılarak mermer sektöründe faaliyet gösteren büyük ölçekli bir işletmede anket uygulanmış ve elde edilen veriler, bulgular yorumlanmak suretiyle ölçeğin geçerliliği test edilmiştir.

\section{LİTERATÜR TARAMASI}

Kültür aynı çevrede yaşayan insanların paylaştığı tüm değerleri, seremonileri, gelenek ve görenekleri, dil, din, sosyal yaşamlarını șekillendiren toplumsal bir kavramdır. Gerek toplumsal yönden gerekse işletmeler perspektifinden oldukça önemsenmiş ve irdelenmiştir. Kültür en kısa tanımıyla ortak paylaşılan değerler bütünüdür.

Kültür kavramı ilk olarak 1871 yılında Edward Taylor tarafından kullanılmıştır. Antropolojiden alınan bir kavram olarak kültür, işletmelerde kazandığı yeni nitelikler ile örgüt kültürü olarak anılmaya başlanmış ve "The Changing Culture of a Factory" kitabıyla Elliott Jaques 1952'de ilk kez bu kavramı kullanmıștır (Muratovic, 2013: 63). 1970'li yıllarda insan kaynakları yönetimi kavramıyla örgüt ve yönetim alanında önemli gelişmeler yaşanmaya başlamıştır. İnsan kaynakları yaklaşımı, yönetim alanında yeni kuramsal çerçevenin oluşmasını sağlamıştır. 1981 yılında William Ouchi, yazdığı Teori-Z kitabıyla örgütsel kültür kuramının kuramsal temelini atmıştır. Sonrasında Deal ve Kennedy ve Edgar H. Schein örgütsel kültürü kuramının gelişmesine katkıda bulunmuşlardır. Thomas J. Peter ve Robert H. Waterman'ın katkıları ise mükemmele ulaşan örgütleri tanımlamışlardır (Aydınlı, 2003: 81). Örgüt kültürü konusunda, sosyologların (Swindler,1986), psikologların (Schneider, 1990), örgütsel davranış araştırmacılarının (Schein, 1992) antropologların (Barley, 1983), yönetim danışmanları ve popüler araştırmacıların (Pascale; Athos 1981, Deal; Kennedy, 1982-Peters; Waterman, 1987) organizasyon teorisyenlerinin (Harrison; Carroll, 1991), stratejik yönetim araştırmacılarının (Barney, 1986) katılımıyla oluşan çalışmalar göze çarpmaktadır (Sayılar, 2003:132). Kültür 1980'lerin başına kadar örgütle bağlantılı bir kavram değildi. Ouchi, 1981; Pascale ve Athos, 1981; Peters ve Waterman, 1982; Deal ve Kennedy, 1982 gibi bilim adamlarının araștırmalarıyla kültür kavramına ciddi dikkat gösterilmeye başlanmıştır (Cameron ve Quinn, 1999: 116).

Literatüre baktığımızda; Davis ve Steven (2018) kültürel değişim sürecinde önemli olan unsurları incelemişler ve uygulamada Cameron ve Quinn örgüt kültürü ölçeğini kullanmışlardır. Pasricha vd. (2018) liderlik, kültür ve kurumsal sosyal sorumluluk üzerine araştırma gerçekleştirmiştir. Ristino vd. (2018) örgüt kültürünün işgören davranış ve tavırlarına etkisini araştırmıştır. Çalışmada çalışanların rapor ettikleri kültürün örgütsel yaşam algıları üzerinde en fazla etkiye sahip olduğunu ortaya koymuşlardır. Daher (2016) örgüt kültürü ve inovasyon arasındaki ilişkiyi incelemiştir. Çalışmasında, örgüt kültürü, inovasyon ve inovasyon modellerini incelemiştir. Örgütsel inovasyon ve örgüt kültürü arasındaki ilişkiyi göstermek için kavramsal bir çerçeve önermektedir. Valencia vd. örgüt kültürü, inovasyon ve performans ilişkisini ispanya'daki işletmelerde Cameron \& Quinn örgüt kültürü ölçeği sınıflamasıyla araştırmışlardır. Yücel \& Koçak(2014) örgüt kültürü ve örgütsel bağlılık arasındaki ilişkiyi, Smith vd. (2012) örgüt kültürünü incelemişlerdir. Munley(2011) çalışmasında liderlikteki kültürel farklılıkların kapsamlı bir incelemesini yapmış ve Geert Hofstede ve GLOBE'nin (Global Liderlik Örgütsel Davranışsal Etkinliği) çalıșmalarını inceleyerek ülkeler arasındaki kültürel farklılıkların anlaşılmasının önemini vurgulamıştır. Örgüt kültürü alanına yaptığı katkılarla bilinen Shein E. (2010) kültür ve liderlik arasındaki ilişkiyi araştırmıştır. Mooji ve Hofstede (2010) Hofstede kültürel boyutları adlı eserlerinde kültür boyutları üzerinde durmuşlardır. Erdem vd. (2010) akademik personelin kurumlarındaki örgüt kültürü eğilimlerini Cameron ve Quinn örgüt kültürü ölçeğiyle incelemişlerdir. Cameron ve Quinn (1999) örgüt kültürünün teşhisi ve değişimi isminde kitaplarıyla literatürde yer almışlardır. Kültür ve örgüt kültürü üzerinde çalışmaları bu alanda çalışan tüm araştırmacılar tarafından takip edilmiş olan Hofstede (1981) Örgütler ve Kültürler eserinde kültürün boyutları üzerinde durmuştur.

KOCATEPEIIBBF Dergisi - Cilt: 21, Sayı: 1, Yll: Haziran 2019, Sayfalar: 19-30.

KOCATEPEIIBF Journal - Volume: 21, Issue: 1, Year: June 2019, Pages: 19-30. 


\section{1. Örgüt Kültürü Kavramı}

Örgütsel davranış çalışmalarında önemli bir kavram olan örgüt kültürü; bir organizasyonu bir arada tutan organizasyon üyelerinin paylaştığı sosyal ve normatif değerler ve inançlar olarak tanımlanır (Alkharabsheh, 2017: 239). Kültür literatürde özellikle sosyoloji ve antropoloji alanında çok fazla araştırılmış bir kavramdır. En basit tanımıyla ortak paylaşılan değerler, inançlar, seremoniler, düşünceler, yaşam biçimidir. Kültür insanın geçmişi, bugün ve geleceğine ait tüm unsurları içinde barındırır.

Örgüt kültürü, örgüt üyelerinin ortak sahip olduğu değerler, inançlar ve gizli varsayımlar olarak tanımlanabilir (Naranjo-Valencia vd., 2016: 32). Kültür, temel olarak sembollerle, sembollerin insan el sanatlarındaki özgün başarılarını oluşturan sembolik düşünme, hissetme ve tepki verme, kazanma ve aktarma şekillerinden oluşur; kültürün temel çekirdeği geleneksel fikirlerden ve özellikle de bunlara bağlı değerlerden oluşur (Hofstede, 1981: 23). Örgüt kültürü, insan gruplarının ayırt edici kazanımlarını oluşturan, sembollerle edinilen ve iletilen davranış kalıpları, açık ve örtük kültür sistemleri olarak tanımlanabilir (Munley, 2011: 24).

\subsection{Cameron ve Quinn Örgüt Kültürü Ölçeği}

Cameron ve Quinn örgüt kültürü ölçeği Klan kültürü, Adokrasi kültürü, Hiyerarşi kültürü ve Piyasa kültürü olmak üzere dört boyuttan oluşur. Her bir boyutun kendi içinde farklı ilkeleri mevcuttur. Klan kültürü bağlılık, katılım, takım çalışması, aile olma ilkelerine, Adokrasi kültürü, yaratıcılık, yenilikçilik ve risk alma üzerine, Hiyerarși kültürü emir komuta düzeni, kurallar ve düzenlemeler, verimlilik üzerine, Piyasa kültürü ise rekabet, çevre ve etkileşim üzerine odaklanır.

Şekil 1. Cameron ve Quinn Örgüt Kültürü Tiplerinin Özellikleri

\begin{tabular}{|l|l|}
\hline KLAN KÜLTÜRÜ & ADOKRASİ KÜLTÜRÜ \\
*Bağlılık & *Yaratıcılık \\
*Katılım & *Yenilikçilik \\
*Takım çalışması & *Risk Alma \\
*Aile Olma & \\
\hline HiYERARŞI KÜLTÜRÜ & PIYASA KÜLTÜRÜ \\
*Emir komuta düzeni & *Rekabet \\
*Kural ve düzenlemeler & *Çevre ile etkileşim \\
*Verimlilik & \\
\hline
\end{tabular}

Piyasa kültürü, pazarın kendisi olarak işlev gören bir organizasyon türünü ifade eder. İşletmenin iç süreçleri yerine dış çevreye yöneliktir. Tedarikçiler, müşteriler, lisans sahipleri, sendikalar ve düzenleyiciler gibi dış çevreyle yapılan işlemlere odaklanır. Hiyerarşi kültürüne uygun organizasyon kültürü, çalışmak için resmi ve yapılandırılmış bir yer ile karakterize edilir. Prosedürler insanların ne yaptığını yönetir. Etkili liderler iyi koordinatörler ve düzenleyicilerdir. Düzgün bir organizasyonun kurulması önemlidir. Resmi kurallar ve politikalar organizasyonu bir arada tutar. Klan kültürünü benimsemiş işletmelerde, paylaşılan değerler ve hedefler, uyum, katılım, bireysellik ve "bizlik" duygusu önemlidir. Bu tip işletmeler ekonomik varlıklardan ziyade geniş ailelere benzerler. Hiyerarşi kültürünün kuralları ve prosedürleri veya piyasa kültürünün rekabetçi kâr merkezleri yerine, klan kültürünün tipik özellikleri ekip çalışması, çalışanların katılım programları ve çalışanların kurumsal bağlılıklarıdır. Adokrasi kültüründe, hiyerarşilerden farklı olarak, odaklanılan bir güç veya otorite ilişkileri yoktur. Bunun yerine, güç, o anda hangi sorunun ele alındığına bağlı olarak bireyden bireye veya görev ekibinden görev ekibine değişir. Adokrasi kültüründe yenilik ve yaratıcllı, risk alma odaklanılan kavramlardır (Cameron ve Quinn, 1999: 37-44).

Klan kültürü, kurumun iç kontrolünü sağlamaya çalışan, ancak esnekliği olan, çalışanları hakkında endişelenen işletmelerde görülür. Adokrasi kültürü, kurumun diş yönlerine odaklanan, yüksek derecede esneklik ve yenilik arayan şirketlerle ilgilidir. Piyasa kültürü, işletmenin dış yönelimini vurgulayan işletmelerde görülür, ancak aynı zamanda kontrol ve iç istikrar ihtiyacı da göz önünde bulundurulur. Hiyerarşi kültürü, kontrol ve istikrar isteyen iç yönlere özellikle dikkat eder (Durendez vd., 2011: 143).

Cameron ve Quinn örgüt kültürü ölçeği Rekabet Değerleri Çerçevesi olarak bilinen teorik bir modele dayanmaktadır. Bu çerçeve çok çeşitli örgütsel olayları organize etmek ve yorumlamak için son derece yararlıdır. (Cameron ve Quinn, 1999: 31). Bu model kültürle ilgili sınıflamalar içerisinde bir değerlendirme ve ölçüm aracını da içermesi sebebiyle yaygın bir şekilde kullanılmaktadır. Bu modelde örgütün kültürü, bir bütün olarak değerlendirilmektedir. Modelde "en iyi" tek bir kültür tipi olduğunu söylemek yanlış olmakla birlikte, bir örgütün, bu tipolojilerden yalnızca bir tanesini benimsemesi çoğunlukla mümkün olmamakta, bunun yerine birden fazla örgüt tipine ait özelliklerin örgütte yaşatılması söz konusu olabilmektedir (Acaray vd., 2015: 142). 


\section{METODOLOJİ}

\subsection{Veri Toplama Yöntemi}

Çalışmada Cameron ve Quinn örgüt kültürü ölçeği uygulanmıştır. Cameron ve Quinn (1999) örgüt kültürü ölçeğinin gerek yabancı, gerek yerli literatürde kullanımı incelenmiş, yabancı literatürdeki çalışmalardan Durendez (2010), Cameron ve Quinn (1999) 'dan ve OCAI (Organizational Culture Assessment Instrument)'den elde edilen anket soruları İngilizceden Türkçeye çevrilmiştir. Alanında uzman akademisyenlerin ifadeleri kontrol sürecinden sonra yerli literatürde kullanımı ile karşıllaştırılarak ifadelerdeki anlam kayıpları giderildikten sonra uygulama sürecine geçilmiştir.

Anketler Afyonkarahisar'da mermer sektöründe faaliyet gösteren büyük ölçekli bir işletmede gerçekleștirilmiştir. Bu işletmenin seçilme nedeni 250 den fazla çalışana sahip, sektörde lider işletme olması ve nesiller boyu uzun yıllar varlığını sürdürmesi dolayısıyla güçlü bir örgüt kültürüne sahip olacağı düşüncesidir. İşletmede çalışanları için 270 adet anket gerçekleştirilmiş ve elde edilen anketlerden kimisinde veri eksikliği tespit edilmiș olup bu sebeple 246 katılımcının cevapladığı anketler araștırma kapsamına alınmıștır.

\subsection{Veri Değerleme Tekniği}

Çalışmada kullanılan anket iki boyuttan oluşmaktadır. İlk bölümde demografik özelliklerin (yaş, cinsiyet, medeni durum, eğitim durumu,) yer aldığı sorular yer almaktadır. İkinci kısımda örgüt kültürünün belirlenebilmesi için ölçek maddeleri " $1=$ Kesinlikle katılmıyorum, $2=$ Katılmıyorum, $3=$ Kararsızım, 4=Katılıyorum, 5=Kesinlikle katılıyorum" șeklinde değișen cevapları içeren 5'li Likert tipi soruların kullanıldığı Cameron ve Quinn örgüt kültürü ölçeği kullanılmıştır. Cameron ve Quinn örgüt kültürü ölçeği Klan kültürü, Adokrasi kültürü, Piyasa kültürü ve Hiyerarşi kültürü olarak dört boyuttan oluşmaktadır. Her boyut dörder ifade içermektedir. Ölçek toplam 16 ifadeden oluşmaktadır.

Analizler kapsamında ilk olarak çalışmada kullanılan Cameron ve Quinn örgüt kültürü ölçeğine geçerlilik analizi uygulanmıştır. Bu çerçevede yapı geçerliliğini test edebilmek için doğrulayıcı faktör analizinden yararlanılmıștır (Meydan ve Şeșen 2015). Geçerlilik analizinin ardından ölçeğe güvenilirlik analizi uygulanmıştır. Veriler SPSS 16,0 paket programına girildikten sonra ölçeğin güvenilirliğinin belirlenmesinde Cronbach Alfa $(\alpha)$ istatistiği kullanılmıştır ve geçerlik analizinde AMOS 19 programında yapısal eşitlik modellemesi gerçekleştirilmiştir.

\subsection{Katılımcıların Demografik Özellikleri}

Anketi cevaplayanların demografik özellikleri kapsamında cinsiyet, medeni durum, yaş ve eğitim seviyeleri sorulmuştur. Yaş kapsamında 20-25 yaş, 26-30 yaş, 31-35 yaş, 36-40 yaş ve 41 yaş üstü olarak. Eğitim durumunda, ilköğretim, lise, önlisans, lisans ve üstü olarak dört sınıflama yapılmıştır.

Tablo 1. Demografik Özellikler

\begin{tabular}{|c|c|c|c|c|}
\hline & & Katılımcı Sayısı & Katılımcı Sayısı \% & Toplam \% \\
\hline \multirow[t]{2}{*}{ Cinsiyet } & KADIN & 32 & 13,0 & 13,0 \\
\hline & ERKEK & 214 & 87,0 & 100,0 \\
\hline \multirow{2}{*}{ Medeni Durum } & BEKAR & 66 & 26,8 & 26,8 \\
\hline & EVLİ & 180 & 73,2 & 100,0 \\
\hline \multirow{5}{*}{ Yaş } & $20-25$ & 41 & 16,7 & 16,7 \\
\hline & $26-30$ & 70 & 28,5 & 45,1 \\
\hline & $31-35$ & 66 & 26,8 & 72,0 \\
\hline & $36-40$ & 35 & 14,2 & 86,2 \\
\hline & 41 YAȘ ÜSTÜ & 34 & 13,8 & 100,0 \\
\hline \multirow{5}{*}{ Eğitim } & İLKÖĞRETIM & 108 & 43,9 & 43,9 \\
\hline & LiSE & 107 & 43,5 & 87,4 \\
\hline & ÖNLISANS & 13 & 5,3 & 92,7 \\
\hline & LİSANS ve ÜSTÜ & 18 & 7,3 & 100,0 \\
\hline & Total & 246 & 100,0 & \\
\hline
\end{tabular}

Afyonkarahisar'da mermer sektöründen faaliyet gösteren büyük ölçekli bir üretim tesisinde yapılan araştırmaya katılan 270 çalışandan 246 sağlıklı veri elde edilmiştir. Bu 246 anketi cevaplayanların 214'ü erkek (\%87), 32'si (\%13) kadın, 180'i (\%73,2) evli, 66'sı (\%26,8) bekârdır. Örneklemi oluşturanların 
yaşlarına bakıldığında, 41'i (\%16,7) 20-25 yaş, 70'i (\%28,5) 26-30 yaş, 66'sı $(\% 26,8)$ 31-35 yaş, 35’i $(\% 14,2)$ 36-40 yaş ve 34'ü $(\% 13,8) 41$ yaş üzerindedir. Örneklemin 108'i $(\% 43,9)$ ilköğretim, 107'si $(\% 43,5)$ lise, 13 ’ü $(\% 5,3)$ önlisans, 18'i $(\% 7,3)$ lisans ve üstü eğitim almıştır.

\subsection{Bulgular}

Tablo 2. Ölçek Cronbach Alfa Katsayısı

\begin{tabular}{|c|c|c|}
\hline \multicolumn{3}{|c|}{ Güvenilirlik İstatistikleri } \\
\hline Cronbach's Alpha & Cronbach's Alpha Based on Standardized Items & $\mathrm{N}$ \\
\hline, 870 &, 897 & 16 \\
\hline
\end{tabular}

Tablo 2 incelendiğinde Örgüt kültürü ölçeğinin yüksek güvenilirlikte ve ölçekteki ifadelere verilen cevapların tutalı olduğu görülmektedir.

$>0,00 \leq \alpha<0,40$ ise ölçek güvenilir değildir,

$>0,40 \leq \alpha<0,50$ ise ölçek çok düşük güvenilirliktedir,

$>0,50 \leq \alpha<0,60$ ise ölçek düşük güvenilirdir,

$>0,60 \leq \alpha<0,70$ ise ölçek yeterli güven düzeyindedir,

$>0,70 \leq \alpha<0,90$ ise ölçek yüksek güvenilirliğe sahiptir,

$>0,90 \leq \alpha<1,0$ ise ölçek çok yüksek derecede güvenilir bir ölçektir.

Kaynak: Özdamar, K.(2015), Paket Programlar ile İstatistiksel Veri Analizi, Nisan Kitabevi, Eskişehir, s.575.

Tablo 3. Ölçekteki Soruların Güvenilirliği

Ölçekteki Soruların Güvenilirliği

\begin{tabular}{|l|c|c|}
\hline \multicolumn{2}{|c|}{ Ölçekteki Soruların Güvenilirliği } \\
\hline İfadeler & Madde sayısı & If Item Deleted Cronbach's Alpha \\
\hline Klan Kültürü 1 & 1 &, 859 \\
\hline Klan Kültürü 2 & 2 &, 859 \\
\hline Klan Kültürü 3 & 3 &, 857 \\
\hline Klan Kültürü 4 & 4 &, 859 \\
\hline Adokrasi Kültürü 1 & 5 &, 859 \\
\hline Adokrasi Kültürü 2 & 6 &, 857 \\
\hline Adokrasi Kültürü 3 & 7 &, 861 \\
\hline Adokrasi Kültürü 4 & 8 &, 862 \\
\hline Piyasa Kültürü 1 & 9 &, 860 \\
\hline Piyasa Kültürü 2 & 10 &, 858 \\
\hline Piyasa Kültürü 3 & 11 &, 863 \\
\hline Piyasa Kültürü 4 & 12 &, 960 \\
\hline Hiyerarşi Kültürü 1 & 13 &, 861 \\
\hline Hiyerarşi Kültürü 2 & 14 &, 862 \\
\hline Hiyerarşi Kültürü 3 & 15 & \\
\hline Hiyerarşi Kültürü 4 & 16 & \\
\hline
\end{tabular}

Tablo 3 incelendiğinde, ölçekteki alt boyutlar için hesaplanan güvenilirlik değerlerinin en düşüğü 0,857 dır. $\mathrm{Bu}$ da gösteriyor ki ifadelerin hiç biri ölçeğin güvenirlik düzeyine olumsuz etki yapmamaktadır. Daha açık bir ifadeyle ölçekten çıkarttığımızda güven düzeyinde anlamlı bir yükselme meydana getirmiyor demektir. 
Tablo 4. Ölçek KMO Değeri

\begin{tabular}{|l|l|c|}
\hline \multicolumn{2}{|c|}{ KMO and Bartlett's Test } \\
\hline Kaiser-Meyer-Olkin Measure of Sampling Adequacy. &, 878 \\
\hline Bartlett's Test of Sphericity & Approx. Chi-Square & $2,044 \mathrm{E} 3$ \\
\cline { 2 - 3 } & Df & 120 \\
\cline { 2 - 3 } & &, 000 \\
\hline
\end{tabular}

KMO: 1,00 $\leq$ KMO0,90= Mükemmel

KMO: 0,90 $\leq K M O 0,80=$ İyi

KMO: 0,80 $\leq K M 00,70=$ Orta düzey

KMO: 0,70 $\leq M 00,60=$ Zayıf

KMO: 0,60 $K M O=$ Kötü

Ölçeğe bakıldığında araştırmanın KMO değeri için çıkan sonucu iyi değerdedir.

Tablo 5. Kültür Ölçeğinin İfadeleri Arasındaki Korelasyon

\begin{tabular}{|c|c|c|c|c|}
\hline \multicolumn{5}{|c|}{ Korelasyon } \\
\hline & 1 & 2 & 3 & 4 \\
\hline Klan Kültürü & 1 &, $712^{* *}$ & $628^{* *}$ & $486^{* *}$ \\
\hline Adokrasi Kültürü &, $712^{* *}$ & 1 & $689^{* *}$ &, $518^{* *}$ \\
\hline Piyasa Kültürü &, $628^{* *}$ &, $689^{* *}$ & 1 &, $513^{* *}$ \\
\hline Hiyerarși Kültürü &, $486^{* *}$ &, $518^{* *}$ &, $513^{* *}$ & 1 \\
\hline
\end{tabular}

${ }^{* *} \mathrm{p}<0,01$

* $\mathrm{p}<0,05$

Tablo 5'de Ölçekte yer alan dört boyutun korelasyon değerleri verilmiştir. Korelasyonlar hesaplanmadan önce bireylerin ölçekteki boyutlara verdiği puanların ortalamaları alınarak, her birey için bir değişken puanı oluşturulmuş ve bu puan değerlendirmeye alınmıştır. Tabloda görüldügü üzere ölçekte yer alan tüm boyutların arasındaki korelasyonun anlamlı ( $\mathrm{p}<0.01)$ olduğu ve korelasyon katsayılarının , 486 ile ,712 arasında değiştiği görülmektedir.

Korelasyon katsayısı -1 ile +1 arasında değer alır. Korelasyon katsayısının alacağı değerlere göre $(0<\mathrm{r} \leq 0.3$, zayıf; $0.3<r \leq 0.7$ orta; $0.7<r \leq 1$ kuvvetli) değişkenler arasındaki ilişki düzeyi yorumlanabilir(Gürbüz, Şahin, 2014: 254).

Klan kültürü Adokrasi kültürü ile $(r=, 712$, p<0.01) en yüksek korelasyon kuvvetli düzeyde, Piyasa kültürü ile $(r=, 628, p<0.01)$ ve Hiyerarşi kültürü ile $(r=, 486, p<0.01)$ orta düzeyde ilişkilidir.

Adokrasi kültürü Klan kültürü ile $(r=, 712$, p<0.01) kuvvetli, Piyasa kültürü ile $(r=, 689, p<0.01)$ ve Hiyerarşi kültürü ile $(r=, 518, p<0.01)$ orta düzeyde ilişkilidir.

Piyasa kültürü Klan kültürü ile(r=,628, p<0.01) orta, Adokrasi kültürü ile $(r=, 689, p<0.01)$ ve Hiyerarşi kültürü ile $(r=, 513, p<0.01)$ orta düzeyde ilişkilidir.

Hiyerarşi kültürü Klan kültürü ile $(r=486, p<0.01)$ orta, Adokrasi kültürü ile (r=,518, p<0.01) ve Piyasa kültürü ile $(r=, 513, p<0.01)$ orta düzeyde ilişkilidir. 


\subsection{Araştırmada Kullanılan Ölçeğin Yapısal Eşitlik Modeli ile Test Edilmesi}

Tablo 6. Ölçekte Yapılan Değișiklikler

\begin{tabular}{|l|l|c|c|}
\hline \multicolumn{2}{|c|}{} & İfade Sayısı & \multicolumn{1}{c|}{$\begin{array}{c}\text { Çlkarılan } \\
\text { Iffade Sayısı }\end{array}$} \\
\hline $\begin{array}{l}\text { Cameron ve Quinn Örgüt } \\
\text { Kültürü Ölçeği }\end{array}$ & Klan Kültürü & 4 & 1 \\
\cline { 2 - 4 } & Adokrasi Kültürü & 4 & - \\
\cline { 2 - 4 } & Piyasa Kültürü & 4 & - \\
\cline { 2 - 4 } & Hiyerarşi Kültürü & 4 & 1 \\
\hline
\end{tabular}

Araştırmada elde edilen verilerin SPSS ile analizlerinde Cronbach's Alpha değeri ölçeğin yüksek güvenilirlikte, KMO değeri iyi değerde olduğunu göstermiştir. Tablo 7'de ölçekte DFA değerleri incelendiğinde ölçeğin iyi uyum değerleri doğrultusunda "Modification İndices" verileri kullanılarak Klan kültüründen bir ve Hiyerarşi kültüründe yer alan bir ifade ölçekten çıkarılmıştır. Bu iki ifade çıkarıldıktan sonra Tablo 7'de de görülmektedir ki ölçek iyi uyum değerleri yükselmiştir. Çıkartılan Klan kültürüne ve Hiyerarşi kültürüne ait iki ifadeden sonra ölçek değerleri iyi uyum değerlerini sağlamıştır. İfadeler çlkarılmadan önce kabul edilebilir uyum değerlerinde olan GFI, CFI, RMSEA ve $x 2 / d f$ değeri iyi uyum değeri almıştır.

Kullanılan ölçeğin geçerliliğini test etmek amacıyla AMOS 19 programıyla tek faktörlü doğrulayıcı faktör analizi yapılmıştır.

Tablo 7. Ölçeğin Uyum Değerleri

\begin{tabular}{|l|c|c|c|c|c|c|}
\hline & $x 2$ & Df & $x 2 / d f$ & GFI & CFI & RMSEA \\
\hline Cameron\& Quin Kültür Ölçeği & 94,124 & 70 & 1,34 &, 95 &, 99 &, 03 \\
\hline İfade çıkarmadan önceki değerler & 256,293 & 97 & 2,64 &, 89 &, 92 &, 08 \\
\hline İyi Uyum Değerleri & & & $\leq 3$ & $\geq 90$ & $\geq 0,97$ & $\leq 0,05$ \\
\hline Kabul Edilebilir Uyum Değerleri & & & $\leq 5$ & $\begin{array}{c}0,89- \\
0,85\end{array}$ & $\geq 95$ & $0,06-0,08$ \\
\hline
\end{tabular}

p >.05, $x 2$ =Chi- Square (Ki-kare); df= Degree of Freedom (Serbestlik Derecesi); GFI= Goodness of Fit Index (İyilik Uyum İndeksi); CFI= Comparative Fit Index (Karşılaştırmalı Uyum İndeksi; RMSEA= Root Mean Square Error of Approximation (Yaklaşık Hataların Ortalama Karekökü).

Kaynak: Meydan ve Şeşen, 2015:37.

x2: Gözlenen(observed) kovaryans matrisi ile kestirilen kovaryans matrisi arasındaki farkın anlamlılığını test etmektedir. RMSEA: (Root Mean Square Error of Approximation) Tahmin hatalarının ortalamasının kareköküdür. RMSEA bilinmeyen fakat optimum șekilde planlanmış parametrelerin, ana kütlenin kovaryans matrisi ile ne derece uyumlu olup olmadığı hakkında bilgi veren bir istatistiktir. GFI (Goodness of Fit Index) Ki-Kare istatistiğinin örneklem büyüdükçe yükselmesi sorununu ortadan kaldırmak üzere ortaya çıkarılmıştır. GFI istatistiği 0 ile 1 arası değer almaktadır ve serbestlik derecesiyle ters orantılı olarak hareket eder. CFI (Comparative Fit Index) CFI, NFI istatistiğinin geliştirilmiş versiyonudur ve kullanılan istatistiklerden biridir. (Yaşlıoğlu, 2017:80-81)( Meydan ve Şeşen, 2015:32-35).

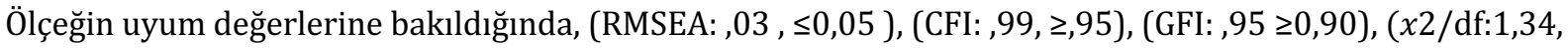
$\leq 5)$ değerleriyle iyi uyum değerlerindedir.

RMSEA değeri çalışmada ,03 çıkmıştır. kabul edilebilir uyum değeri ,06-,08 arasında gerçekleşmesi yönündedir. Bu anlamda RMSEA değeri iyi uyum değerini karşılamaktadır. CFI çalışmada elde edilen değer ,99'dir. İyi uyum değeri ,97 olmakla, örnek iyi uyum değerlerindedir. GFI çalışmada ,95'dir. GFI iyi uyum değeri ,90 ve üzeri olması beklenir. Dolayısıyla iyi uyum değerdedir. $x 2 / d f$ çalışmada 1,34 olarak hesaplanmıştır. İyi uyum değeri olan 3 den küçüktür. Yani iyi uyum değeri olan $\leq 3$ şartını sağlamıştır. 
Tablo 8. Demografik Özellikler ve DFA Katsayıları

\begin{tabular}{|c|c|c|c|c|c|c|c|c|c|c|c|c|c|c|c|c|c|c|c|c|c|c|c|c|}
\hline & & & & & ב & & & 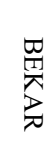 & & & 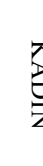 & & & $\begin{array}{l}\text { 窎 } \\
\text { 基 }\end{array}$ & & & $\begin{array}{l}7 \\
38 \\
3\end{array}$ & & & 莺. & & & 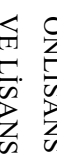 & \\
\hline & $\checkmark$ & $\underset{N}{D}$ & $\approx$ & $\nabla$ & $\mathbb{N}_{N}$ & $\approx$ & ס & $D_{N}^{-}$ & $\nexists$ & $\checkmark$ & $\nabla_{N}$ & $\approx$ & $\sigma$ & $D_{N}$ & 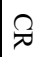 & $\tau$ & $D_{N}$ & $\approx$ & $\nabla$ & $\underset{N}{D}$ & $\approx$ & $\nabla$ & $D_{N}$ & $\approx$ \\
\hline I & $\stackrel{*}{*}$ & $\underline{w}$ & $\stackrel{a}{a}$ & $\stackrel{*}{*}$ & 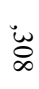 & $\stackrel{a}{\dot{\alpha}}$ & 兽 & $\vec{a}$ & $\begin{array}{l}- \\
\dot{0} \\
\text { U. }\end{array}$ & 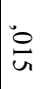 & $\underset{\perp}{\stackrel{\sim}{\sim}}$ & 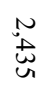 & * & $\ddot{\infty}$ & $\stackrel{a}{N}$ & * & $\begin{array}{l}u^{\prime} \\
\stackrel{t}{0}\end{array}$ & 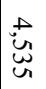 & 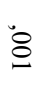 & $\vec{A}$ & $\begin{array}{l}\omega \\
\omega \\
\infty \\
\infty\end{array}$ & 芫 & $\dot{u}$ & $\begin{array}{l}N \\
\stackrel{N}{0} \\
\stackrel{0}{0}\end{array}$ \\
\hline 更 & $\begin{array}{l}* \\
* \\
*\end{array}$ & 点 & $\begin{array}{l}\stackrel{\sim}{N} \\
\stackrel{A}{ \pm}\end{array}$ & $\begin{array}{l}* \\
* \\
*\end{array}$ & $\stackrel{ \pm}{v}$ & $\begin{array}{l}\overrightarrow{0} \\
\stackrel{0}{0}\end{array}$ & 嗢 & ఝ̆. & : & "̈ & 定 & 空 & * & 离 & $\stackrel{\vartheta}{\partial}$ & $\begin{array}{l}* \\
* \\
*\end{array}$ & 怘 & $\begin{array}{l}\vec{t} \\
\dot{0} \\
\text { I }\end{array}$ & * & $\stackrel{ \pm}{*}$ & 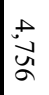 & $\stackrel{\circ}{\infty}$ & $\breve{u ̈ g}^{\stackrel{u}{u}}$ & $\stackrel{\sim}{\tilde{\omega}}$ \\
\hline ' & $\underset{*}{*}$ & $\stackrel{\stackrel{+}{+}}{\mathrm{N}}$ & 党 & * & $\stackrel{\stackrel{N}{N}}{\Delta}$ & $\mid \begin{array}{l}\hat{0} \\
\infty \\
\infty\end{array}$ & 总 & 苍 & : & i & 总 & $\stackrel{5}{\circ}$ & * & is & $\stackrel{\Omega}{N}$ & $\begin{array}{l}* \\
* \\
*\end{array}$ & $\stackrel{ \pm}{N}$ & $\underset{\infty}{\stackrel{\infty}{\infty}}$ & $\begin{array}{l}* \\
*\end{array}$ & $\stackrel{\omega}{\sigma}$ & $\stackrel{\stackrel{+}{\omega}}{\stackrel{\omega}{\varrho}}$ & $\stackrel{\circ}{\circ}$ & $\stackrel{\infty}{\omega}$ & 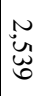 \\
\hline 百 & & $\frac{i}{a}$ & & & $\begin{array}{l}u \\
t \\
\Delta\end{array}$ & & & $\stackrel{\overrightarrow{1}}{\circ}$ & & & $\begin{array}{l}\infty \\
\infty \\
\omega \\
\omega\end{array}$ & & & 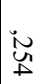 & & & i⿱艹⿻心禸 & & & $\stackrel{u}{u}^{u}$ & & & $\check{\infty}_{u}$ & \\
\hline $\begin{array}{l}\pi \\
\mathbb{C}\end{array}$ & \begin{tabular}{|l}
$*$ \\
$*$ \\
$*$ \\
$*$
\end{tabular} & $\ddot{\Xi}$ & $\begin{array}{l}\circ \\
\vdots \\
\stackrel{ \pm}{\omega} \\
\end{array}$ & * & $\stackrel{\Delta}{\omega}$ & $\begin{array}{l}\sim \\
\infty \\
\sim \\
\sim\end{array}$ & $\begin{array}{l}* \\
* \\
*\end{array}$ & $\underset{\infty}{\breve{m}}$ & $\begin{array}{l}4 \\
\stackrel{1}{*} \\
\stackrel{0}{*}\end{array}$ & \begin{tabular}{|l}
$*$ \\
$*$ \\
$*$
\end{tabular} & $\stackrel{\circ}{\circ}$ & $\begin{array}{l}\omega_{\stackrel{\omega}{\omega}} \\
\stackrel{+}{+}\end{array}$ & * & 芦 & $\begin{array}{l}\infty \\
\infty \\
\stackrel{\infty}{N} \\
N\end{array}$ & * & $\stackrel{i}{u}$ & 岕 & $\stackrel{*}{*}$ & $\stackrel{\mathscr{\infty}_{\infty}}{=}$ & $\stackrel{+}{\stackrel{\Delta}{\sigma}}$ & $\begin{array}{l}* \\
* \\
*\end{array}$ & 䓞 & $\stackrel{\stackrel{\oplus}{\mathbb{N}}}{\stackrel{0}{\circ}}$ \\
\hline 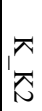 & * & 克 & $\begin{array}{l}0 \\
\text { 岕 } \\
\text { 心 }\end{array}$ & * & $\stackrel{t}{b}$ & $\stackrel{\infty}{\stackrel{\infty}{\infty}}$ & $\begin{array}{l}* \\
* \\
*\end{array}$ & 岕 & 空 & 竞 & $\bar{u}$ & $\begin{array}{l}n \\
\stackrel{8}{8} \\
8\end{array}$ & * & 点 & $\begin{array}{l}0 \\
\stackrel{\sim}{\sim} \\
\text { U. }\end{array}$ & $\begin{array}{l}* \\
* \\
*\end{array}$ & $\ddot{\breve{\omega}}$ & $\begin{array}{l}\stackrel{0}{\Lambda} \\
\pm\end{array}$ & * & 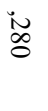 & $\stackrel{\stackrel{+}{\sim}}{\underset{\sim}{J}}$ & * & 突 & $\begin{array}{l}\stackrel{+}{\dot{0}} \\
\dot{\omega}\end{array}$ \\
\hline $\begin{array}{l}\pi \\
\mathbb{\omega}\end{array}$ & & ĭ & & & 崩 & & & 恣 & & & $\ddot{u}$ & & & 巃 & $\begin{array}{l}0 \\
u \\
u \\
\hat{0}\end{array}$ & & 拿 & & & $\stackrel{ \pm}{ \pm}$ & & & बे̆ & \\
\hline ' & \begin{tabular}{|l|}
$*$ \\
$*$ \\
$*$
\end{tabular} & $\stackrel{\omega}{\omega}$ & 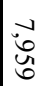 & * & | & 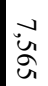 & 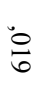 & $\underset{\sim}{\vec{H}}$ & 岕 & 兽 & 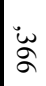 & $\stackrel{5}{\circ}$ & $\begin{array}{l}* \\
* \\
*\end{array}$ & $\stackrel{\ddot{\infty}}{\infty}$ & $\stackrel{\sim}{\grave{D}}$ & * & 叁 & $\begin{array}{l}\text { ur } \\
\text { Ñ } \\
\text { gి }\end{array}$ & $\begin{array}{l}* \\
* \\
*\end{array}$ & 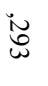 & $\stackrel{+}{\infty}$ & $\stackrel{*}{*}$ & 涊 & $\stackrel{+}{ \pm}$ \\
\hline ' & $\begin{array}{l}* \\
* \\
*\end{array}$ & 宓 & $\begin{array}{l}\infty \\
\stackrel{\infty}{+} \\
\underset{\infty}{\infty}\end{array}$ & $\begin{array}{l}* \\
* \\
*\end{array}$ & 点 & $\mid \begin{array}{l}\infty \\
\stackrel{8}{+} \\
\dot{+}\end{array}$ & $\stackrel{\circ}{\circ}$ & 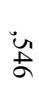 & $\begin{array}{l}n \\
\stackrel{N}{\Delta} \\
\text { Ŭ }\end{array}$ & 辛 & $\stackrel{\infty}{\stackrel{\omega}{\omega}}$ & $\overrightarrow{8}$ & $\begin{array}{l}* \\
* \\
*\end{array}$ & 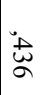 & $\begin{array}{l}\infty \\
\infty \\
\stackrel{1}{1}\end{array}$ & $\begin{array}{l}* \\
* \\
*\end{array}$ & $\underset{\sigma}{\omega}$ & $\begin{array}{l}{ }_{0}^{\prime} \\
\stackrel{0}{\sigma}\end{array}$ & * & $\stackrel{\dot{u}}{\sigma}$ & 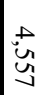 & $\stackrel{*}{*}$ & 岕 & $\stackrel{\vec{\omega}}{\stackrel{\vec{U}}{\sigma}}$ \\
\hline $\begin{array}{l}> \\
\text { 至 }\end{array}$ & $\begin{array}{l}* \\
* \\
*\end{array}$ & in & $\begin{array}{l}\infty \\
\dot{\infty} \\
\stackrel{\omega}{\omega}\end{array}$ & * & $\stackrel{+}{\infty}$ & $\begin{array}{l}\infty \\
\ddot{\partial} \\
\sigma\end{array}$ & $\stackrel{\circ}{\circ}$ & 㐫 & $\mid \begin{array}{c}N \\
+ \\
\infty \\
\infty\end{array}$ & 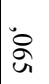 & 苦 & $\begin{array}{l}+\infty \\
+\infty \\
+\infty\end{array}$ & $\stackrel{*}{*}$ & 芯 & $\stackrel{\infty}{\stackrel{\omega}{\omega}}$ & * & $\stackrel{*}{*}$ & $\begin{array}{l}u \\
u \\
u \\
u\end{array}$ & $\stackrel{*}{*}$ & 荘 & ur & $\stackrel{*}{*}$ & $\stackrel{\grave{N}}{\sim}$ & \begin{tabular}{l}
$u$ \\
un \\
\multirow{\infty}{*}{}
\end{tabular} \\
\hline$\stackrel{>}{\triangle}$ & & $\mid \begin{array}{l}u \\
\infty\end{array}$ & & & $\stackrel{ \pm}{ \pm}$ & & & 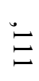 & & & $\stackrel{i}{\perp}$ & & & $\mathscr{D}_{\mathscr{O}}$ & & & 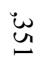 & & & 蕆 & & & $\begin{array}{r}\ddot{m}_{\infty} \\
\dot{\infty}_{\infty}\end{array}$ & \\
\hline 志 & $\stackrel{\circ}{\infty}$ & 诵 & 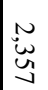 & 总 & & $\stackrel{N}{\tilde{\omega}}$ & $\dot{\omega}$ & & 岕 & $\stackrel{\circ}{\circ}$ & ī & $\stackrel{n}{n}$ & ర్ల్ల & 중 & $\begin{array}{l}\stackrel{N}{\circ} \\
\stackrel{\Xi}{\square} \\
\not\end{array}$ & $\underset{w}{w}$ & $\stackrel{\infty}{\infty}$ & 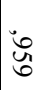 & \& & 嵌 & 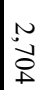 & 尽 & $\stackrel{\stackrel{\sim}{\sim}}{\sim}$ & $\begin{array}{l}\omega \\
0 \\
\ddot{\omega} \\
u\end{array}$ \\
\hline 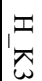 & & io & & & $\stackrel{5}{.}$ & & & is & & & $\begin{array}{l}\infty \\
\infty \\
\perp\end{array}$ & & & 5 & & & 岕 & & & 5 & & & : & \\
\hline I & $\begin{array}{l}* \\
* \\
*\end{array}$ & 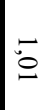 & $\begin{array}{l}\stackrel{\omega}{ \pm} \\
\stackrel{\omega}{\omega}\end{array}$ & $\begin{array}{l}* \\
* \\
*\end{array}$ & & $\begin{array}{l}\omega \\
\stackrel{w}{u} \\
\stackrel{N}{\mathcal{N}}\end{array}$ & $\begin{array}{l}* \\
* \\
*\end{array}$ & N & \begin{tabular}{|l}
$*$ \\
$*$ \\
$*$
\end{tabular} & \begin{tabular}{|l}
$*$ \\
$*$ \\
$*$
\end{tabular} & 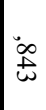 & ه & * & کू & $\begin{array}{l}\breve{u} \\
\ddot{y} \\
\vec{f}\end{array}$ & * & 8 & 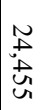 & * & 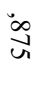 & $\mid \begin{array}{l}\infty \\
\dot{\nu} \\
\text { पू }\end{array}$ & $\stackrel{*}{*}$ & $\stackrel{\circ}{\infty}$ & $\frac{N}{\stackrel{N}{\omega}}$ \\
\hline
\end{tabular}

Ankete katılanların demografik özellikleri de ölçek analizine dâhil edildiğinde yukarıdaki tablo elde edilmiştir. İlk üç sütunda DFA modeli oluşturduktan sonra elde ettiğimiz $\mathrm{p}, R^{2}$ ve CR değerleridir. Bu değerlere ilk önce dahil edilen cinsiyet ve buna bağlı anket sonuçlarının verdiği katsayılardır. Buna göre katılımcıların kadın olanlarının kültür ölçeğine verdikleri cevaplar ile erkek olanların verdiği cevaplar arasında anlamlı faklılık mevcuttur. 
Kadın katılımcıların Piyasa Kültürü 2, Piyasa Kültürü 3, Adokrasi Kültürü 1 ve Adokrasi Kültürü 3 sorularıyla anlamlı fark yoktur. Erkek katılımcllar Hiyerarşi Kültürü 3 ifadesine p<,05 düzeyinde ve diğer ifadeler ise $\mathrm{p}<, 001$ denkliğini sağladığı için sorular üzerine etkili oldukları söylenebilir.

Medeni duruma baktığımızda evli olanların Hiyerarşi Kültürü 2 dışındaki tüm ifadelere olan etkisi p<,001 eşitliğini sağlamaktadır. Bekar olanlarla evli olanların tercihleri anlamlı faklılık göstermemektedir. Bekâr olanlar da Hiyerarși Kültürü 2 ifadesi dışında Medeni durumun sorular üzerine kısmen farklılıktan söz edilebilir. Bekâr katılımcılar Hiyerarşi Kültürü 2 ifadesinde p<,05 eşitliğini sağlayamamıştır.

Eğitim durumunda ise lise ve önlisans-lisans mezunlarının $p$ değerleri $p<, 01, p<, 05$ eşitliğini sağlamakta ilköğretim mezunlarında Hiyerarşi Kültürü 3 p<,01 ve p<,05 eşitliğini sağlayamamıştır yani soruları cevaplamada eğitim unsuru etkili olmaktadır.

\subsection{Doğrulayıcı Faktör Analizi (DFA)}

Cameron ve Quinn örgüt kültürü ölçeğinin dört boyutu çalışmada Piyasa kültürü(P_K), Klan kültürü(K_K), Adokrasi kültürü(A_K), Hiyerarşi kültürü(H_K) olarak kısaltılmıştır.

Şekil 2. Doğrulayıcı Faktör Analizi (DFA) Modeli

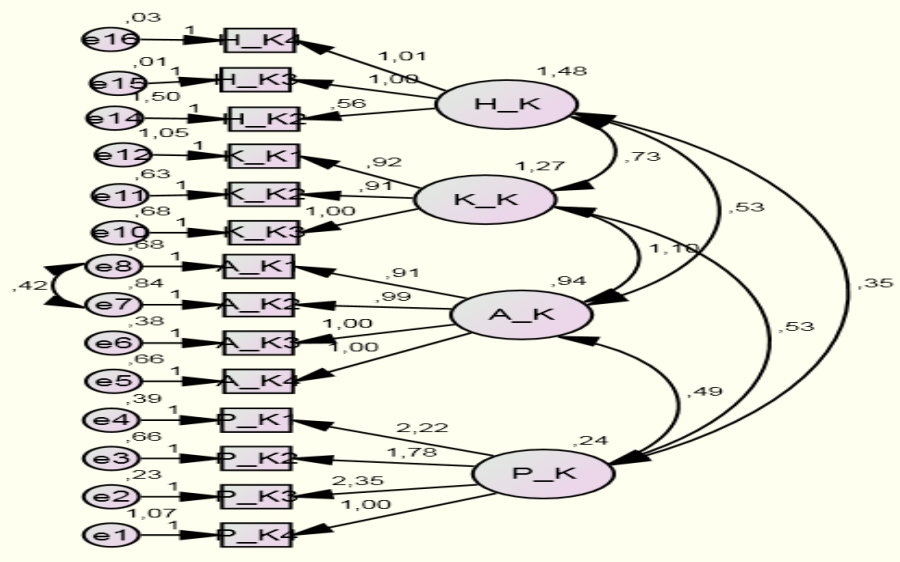

Ölçüm modeli olarak da isimlendirilen DFA, gözlenen değişkenler ile bu gözlenen değișkenler aracılığıyla ölçüldüğü kabul edilen yapı ya da yapılar arasındaki ilişkileri test etmek için kullanılmaktadır (Illhan ve Çetin, 2014: 29). Doğrulayıcı faktör analizi (DFA), ölçme modellerinin geliştirilmesinde sık kullanılan ve önemli kolaylıklar sağlayan bir analiz yöntemidir. Genellikle ölçek geliştirme ve geçerlilik analizlerinde kullanılmakta veya önceden belirlenmiş bir yapının doğrulanmasını amaçlamaktadır (Yaşlığlu, 2017: 78).

Şekil 2'de görülen modelin uyum değerleri kabul edilebilir sınırlarda çıkmadığından Cameron ve Quinn Örgüt Kültürü ölçeğinden iki ifade çıkarılmıştır. Yapılan modifikasyon sonucu modelin uyum değerlerinin iyi uyum değerleri sınırları içinde olduğu ve modelin yapısal olarak uygun olduğuna ilişkin yeterli kanıtların sağlandığ gözlemlenmiştir. 
Tablo 9. Doğrulayıcı Faktör Analizi Katsayıları

\begin{tabular}{|c|c|c|c|c|c|}
\hline Değișkenler & B & Standart hata & P & $R^{2}$ & CR değeri \\
\hline P_K1 & 1,190 &, 176 & ${ }^{*}$ &, 357 & 6,777 \\
\hline P_K2 & 1,453 &, 200 & $* * *$ &, 453 & 6,262 \\
\hline P_K3 & 1,447 &, 201 & $* * *$ &, 442 & 7,211 \\
\hline P_K4 & 1,000 & & &, 276 & \\
\hline K_K1 & 1,003 &, 106 & $* * *$ &, 417 & 9,432 \\
\hline K_K2 &, 817 &, 088 & $* * *$ &, 404 & 9,282 \\
\hline K_K3 & 1,000 & & &, 569 & \\
\hline A_K1 & 1,165 &, 146 & $* * *$ &, 378 & 7,975 \\
\hline A_K2 & 1,191 &, 141 & $* * *$ &, 439 & 8,456 \\
\hline A_K3 & 1,216 &, 135 & $* * *$ &, 514 & 8,981 \\
\hline A_K4 & 1,000 & & &, 380 & \\
\hline H_K2 &, 381 &, 161 &, 018 &, 022 & 2,362 \\
\hline H_K3 & 1,000 & & &, 941 & \\
\hline H_K4 &, 973 &, 028 & $* * *$ & 1,010 & 34,183 \\
\hline
\end{tabular}

Olușturulan modelin katsayıları incelendiğinde, $H_{-}$K2 (p:0,018) dıșında, $p$ değerleri p<0,001 dir. Bu değerle " $p<0,001$ ise her bir faktörün olușmasına katkı veren değișkenlerin tümü önemli düzeyde faktör olușumuna katkı vermişlerdir (Özdamar, 2016:246)". Bu anlamda DFA modikasyon sonrası çıkartığımız iadelerden sonra, ölçeği oluşturan ifadelerin tümü anlamlı çıkmıştır. Modeldeki ifadelerin $R^{2}$ bakıldığında, 0,30 değerinden düşük piyasa kültürüne ait dördüncü ifade ve hiyerarşi kültürüne ait ikinci ifade yer almaktadır. Ölçek yapısal eşitlik modelinde yapılan analizlerde geçerlik düzeyini sağlamıştır.

\section{SONUC}

Bu çalışmada, Cameron ve Quinn (1999) tarafından geliştirilen örgüt kültürü ölçeğinin geçerlik ve güvenirliği Afyonkarahisar'da mermer sektöründe faaliyet gösteren büyük ölçekli bir işletmede analiz edilmiştir. Elde edilen bulgular bu ölçeğin Türkçe'deki güvenirlik ve geçerliğinin uygun olduğuna işaret etmektedir.

Ölçek geçerliliğini tespit etmekte Croncba Alfa değeri ,870 bulunmuştur. Bu da ölçek güvenirliği açısından yüksek güvenirlikte olduğu sonucunu vermektedir. Yapısal eșitlik modelinde oluşturulan DFA değerlerinde p>.05, $x 2$ (Ki-kare); df(Serbestlik Derecesi); GFI; İyilik Uyum İndeksi; CFI; Karşılaştırmalı Uyum İndeksi; RMSEA değerleri kabul edilebilir sınırlarda bulunmuştur. Ölçeğin uyum değerlerine bakıldığında, (RMSEA:

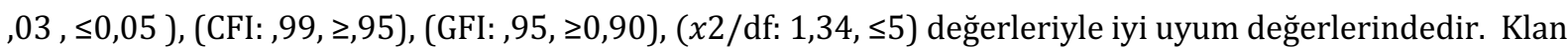
kültürü, Adokrasi kültürü, Piyasa kültürü ve Hiyerarşi kültürü olarak dört boyuttan oluşan ölçeğin korelasyon değerleri incelenmiş ve tüm boyutlarının birbiriyle korelasyon düzeylerinin anlamlı olduğu görülmüştür.

Ölçeğin güvenirlilik ve geçerlilik analiz sonuçları birlikte değerlendirildiğinde çalışmada ölçekten Klan kültürü ve Hiyerarşi kültürü ifadelerinden birer madde çıkarılınca ölçek güvenirliği ve DFA değerleri iyi uyum değerlerinde olduğu görülmüştür. Sonuç olarak Cameron ve Quinn Örgüt Kültürü ölçeğinin 4 alt boyutlu faktör yapısının uygun olduğu, ölçekteki maddelerin geçerliliklerinin yüksek olduğu, güvenilir ve geçerli bir ölçek olduğu bulguları elde edilmiştir. 


\section{KAYNAKÇA}

Acaray, A., Çekmecelioğlu, H.G., Akturan, A. (2015), Örgüt Kültürü ve Örgütsel Sessizlik Arasındaki İlişkinin İncelenmesi, The Journal of Academic Social Science Studies, Number: 32 , p. 139-157., Doi number:http://dx.doi.org/10.9761/JASSS2645

Alkharabsheh, O.H., Alias, R.B., İsmail, M.H.B. (Oct 2017), The Mediating Effect of Organization Culture on Transformational Leadership and Turnover Intention in Jordanian Public Hospitals, International Journal of Business and Management Science.

Aydınlı, H. İ. (2003), Örgüt Kültürünün Yönetim Açısından Önemi, Bilgi (7)/ 2: 79-99.

Cameron, K.S., Quinn, R.E.(1999), Diagnosing and Changing Organizational Culture. Base on the Competing Values Framework, Reading, Mass: Addison-Wesley.

Daher, N. (2016), The Relatıonshıps Between Organızatıonal Culture And Organızatıonal Innovatıon International Journal of Business and Public Administration, Volume 13, Number 2.

Davis,R., Steven, C.(2018), The Implementation of the Organizational Culture Assessment Instrument in Creating a Successful Organizational Cultural Change, Intarnetional Journal of Business and Public Administration, Vol.15, no.1.

Durendez, A., Madrid- Guijarro, A., García-Pérez-de-Lema, D.(2011), Innovative culture, management control systems and performance in small and medium-sized Spanish family firms, rev. innovar vol. 21, núm. 40, abril- junio de.

Erdem, R., Adıgüzel, O., Kaya, A.(2010), Akademik Personelin Kurumlarına İlişkin Algıladıkları Ve Tercih Ettikleri Örgüt Kültürü Tipleri Erciyes Üniversitesi Iktisadi Ve İdari Bilimler Fakültesi D 74 Ergisi, Sayı: 36, Ss.73-88.

Gürbüz, S., Şahin, F. (2014), Sosyal Bilimlerde Araştırma Yöntemleri, Seçkin Yayıncılık.

Hofstede, G. (1981), Culture and Organizations, Int. Studies of Man. \& Org.. Vol. X, No. 4, pp. 15-41.

İlhan, M., Çetin, B. (2014), LISREL ve AMOS Programları Kullanılarak Gerçekleștirilen Yapısal Eșitlik Modeli (YEM) Analizlerine İlişskin Sonuçların Karşılaştırılması, Eğitimde ve Psikolojide Ölçme ve Değerlendirme Dergisi, Cilt 5, Sayı 2, 26-42.

Meydan, C.H., H. Şeşen. (2015), Yapısal Eşitlik Modellemesi Amos Uygulamaları, Detay yayıncılık, Ankara.

Mooji, D.M., Hofstede, G. (2010), The Hofstede model Applications to global branding and advertising strategy and research, Intemationjal Journal of Advertising, 29(1), pp. 85-110.

Munley, A.E. (2011), Culture Differences in Leadership, The IUP Journal of Soft Skills, Vol. V, No. 1, pp.1630.

Muratovic, H. (2013), Buıldıng Competıtıve Advantage Of The Company Based On Changing Organızatıonal Culture, Economic Review - Journal of Economics and Business, Vol. XI, Issue 1.

Naranjo-Valencia, J. C., Jimenez, J.D., Valle, R.S.(2015), Studying the Links Between Organizational Culture, Innovation, and Performance in Spanish Companies, Revista Latinoamericana de Psicologia, 48, 30-41.

Özdamar, K.(2015), Paket Programlar ile İstatistiksel Veri Analizi, Nisan Kitabevi, Eskişehir, s.575.

Özdamar, K.(2016), Ölçek ve Test Geliştirme Yapısal Eşitlik Modellemesi, Nisan Kitabevi, Eskişehir.

Pasricha, P., Singh, B., Verma, P.(2018), Ethical Leadership Organic Organizational Cultures and Corporate Social Responsibility: An Empirical Study in Social Enterprises, J. Bus Ethics, 151:941-958.

Ristino, R.J., Michalak, J.M.(2018), Employee Perceptions of Organizational Cultures Influence on their Attitudes and Behaviours, JEEMS, 23(2), 295-322.

Sayılar, Y., (2003), Kültürel Değişim Kültüre Ne Kadar Duyarlı? Kültürel Değiş̧imin Nedenleri ve Değiişim Süreci Üzerine Bir İnceleme, Uludağ Üniversitesi İktisadi ve İdari Bilimler Fakültesi Dergisi, Cilt XXII, Sayı 2, s. 131-150.

Schein, E.(2010), Organizational Culture and Leadership, Jossey-Bass Wiley Imprint, San Fransisco.

Smith, A., Haimes, G.A., Stewart, B.K.(2012), Organizational Culture And Identity: Sport, Sybols And Success, Nova Science Publishers, Ebook, N.Y. 
Yaşlıŏlu, M.M.(2017), Sosyal Bilimlerde Faktör Analizi ve Geçerlilik: Keşfedici ve Doğrulayıcı Faktör Analizlerinin Kullanılması, İstanbul Üniversitesi İşletme Fakültesi Dergisi, Vol/Cilt: 46, Special Issue/Özel Sayl, 74-85 ISSN: 1303-1732 - http://dergipark.ulakbim.gov.tr/iuisletme.

Yücel, İ., Koçak, D.(2014), Örgüt Kültürü İle Örgütsel Bağlllık Arasındaki İlişkiye Yönelik Bir Araştırma, Erzincan Üniversitesi Sosyal Bilimler Enstitüsü Dergisi (ERZSOSDER) Vılı - Iı : 45 -64. 